\title{
CORRELATION BETWEEN SERUM LEVELS OF FOLLICLE STIMULATING HORMONE AND GRAAFIAN FOLLICLE VASCULARITY ON DOPPLER IN INFERTILE FEMALES OF LAHORE
}

\author{
Amjad Iqbal, Syed Amir Gilani, Asif Hanif \\ University of Lahore-Pakistan
}

\begin{abstract}
Objective: To determine correlation between serum levels of Follicle Stimulating Hormone (FSH) and Graafian Follicle vascularity on Doppler ultrasound in infertile females of Lahore, Pakistan.

Study Design: Cross sectional study.

Place and Duration of Study: Prime Ultrasound Center, Mughalpura, Lahore, Pakistan, from Mar 2018 to Sep 2019.

Methodology: A total of 100 infertile females using simple random sampling were taken. All the married women of reproductive age and married for $>12$ months who did not conceive despite regular unprotected intercourse, having no other uterine and endometrial or ovarian pathology were taken. The patients who failed to provide serum hormone laboratory reports were excluded. Transvaginal ultrasonography was done for all females and Graafian Follicle Vascularity on Doppler was measured on day 12 of the cycle.

Results: The median age of females was 28 (30-25) years ranging from 19 and 46 years. The median FSH levels at day 12 was $6(8.25-5.22) \mathrm{mlU} / \mathrm{ml}$ with minimum and maximum FSH values as 3.20 and $40 \mathrm{mlU} / \mathrm{ml}$. The median follicle size was 13.65 (16.04-10.84) (mm) with minimum and maximum size as $10 \mathrm{~mm}$ and $26 \mathrm{~mm}$. There were $61 \%$ females who had grade- 1 perifollicular vascularity, $24 \%$ females had grade- 2 and $15 \%$ females had grade- 3 of perifollicular vascularity. There was significant positive correlation between perifollicular vascularity grades and (FSH) levels day on $12(\mathrm{~mm})$ i.e., r=0.309, $p$-value $<0.001$.

Conclusion: It is concluded that perifollicular vascularity was found to correlate with serum FSH levels, so Graafian Follicle Vascularity on doppler can be helpful in diagnosis of primary infertility in females in unstimulated cycles. Moreover, doppler ultrasound is helpful for functional assessment of Graafian follicle as it can easily identify vascularity of Graafian follicle, which is expression of hormonal level.
\end{abstract}

Keywords: Assisted reproductive technology, Color Doppler, Follicular vascularity, Graafian follicle, Infertility.

How to Cite This Article: Iqbal A, Gilani SA, Hanif A. Correlation Between Serum Levels of Follicle Stimulating Hormone and Graafian Follicle Vascularity on Doppler in Infertile Females of Lahore. Pak Armed Forces Med J 2021; 71(5): 1687-1692. doi: https://doi.org/10.51253/pafmj.v71i5.7233

This is an Open Access article distributed under the terms of the Creative Commons Attribution License (https://creativecommons.org/licenses/by-nc/4.0/), which permits unrestricted use, distribution, and reproduction in any medium, provided the original work is properly cited.

\section{INTRODUCTION}

Clinically infertility is defined as not being successful to become pregnant despite 12 months or more of regular intercourse of a sexually active couple not on contraception. ${ }^{1}$ Infertility is divided into two types i.e. primary and secondary. Primary infertility is when a couple not on contraception, living together and having regular sexual activity for over a period of one year or more, without ever getting clinical pregnancy. Secondary infertility is when the couple have had at least one clinical pregnancy but afterwards incapable to conceive. ${ }^{2}$ In developing countries like Pakistan and India, with low literacy rate a simple lack of knowledge and neglect about what causes infertility and how it can be treated even in the $21^{\text {st }}$ century becomes a reason for the couples to suffer from social isolation. ${ }^{3,4}$

Infertility is caused by the disturbance of various

Correspondence: Dr Amjad Iqbal, Assistant Professor, PhD Scholar, UIRSMIT, University of Lahore, Lahore Pakistan

Received: 13 Aug 2021; revision received: 15 Aug 2021; accepted: 16 Aug 2021 hormones, e.g. Follicle-stimulating hormone (FSH), Luteinizing hormone (LH), Estradiol, and Progesterone. Normal human reproduction requires orderly working of hypothalamic-pituitary-gonadal axis. Diversion from normal, results in reproductive disorders including different forms of infertility. ${ }^{5} \mathrm{FSH}$ and $\mathrm{LH}$ cause the development and growth of several Primordial Follicles (PF), which secrete estrogen. FSH makes the follicle develop and grow in the ovary before the release of egg at the time of ovulation in addition to its effects on menstrual cycle and in turn chances of getting pregnant. FSH levels thus produced, correlate with quality and quantity of egg and directly influence the chances of conceiving and or sustaining pregnancy. ${ }^{6}$ Women who do not ovulate cannot conceive without Assisted Reproductive Technology (ART). The FSH levels vary throughout the menstrual cycle with a spike immediately before ovulation. FSH levels are measure of ovarian reserve and are assessed to determine the ovarian function and quality of ovum. ${ }^{7}$ 
Diagnostic ultrasound is initial imaging modality for assessment of causes of female infertility. Transvaginal ultrasound (TVUS) being high resolution and imaging the structure from very close is better than transabdominal ultrasound (TAUS). Out of the changes in morphology and vascularity occurring under hormonal influence (gonadotrophins), grayscale TVUS however allows only morphologic assessments of female reproductive structures and ovarian follicle but gives no information about vascular change (functional assessment). These changes in vascularity are reflection of hormonal changes occurring during menstrual cycle and can be studied with Doppler ultrasound. The changes in follicular vascularity reflect functional and physiological maturity of the ovum. So for functional assessment (hormonal induced blood flow changes) of pelvic organs and Mestrual Cycle (MC) we need doppler ultrasound. Doppler ultrasound confirms that ovarian blood flow volume and its velocity varies in various phases of menstrual cycle. Therefore follicular blood flow characteristics can anticipate the possible cause of infertility. ${ }^{8,9}$

The current study was designed to establish the role of doppler ultrasound in detection of infertility while using routine sonographic examination as a simple tool. Currently there are many biomarkers and methods but none of them has gained popularity for detection of infertility as routine procedure. FSH is widely used and there is limited material available on the importance of its correlation with Graafian Follicular Vascularity as per researcher's knowledge in recent past. As vascularization status of ovarian follicle effects the reproductive oocyte and quality of embryo by regulating its oxygen supply. Once the correlation is proven then in future this simple and commonly used modality in obstetrics and gynecology can be used confidently to diagnose ovulation related infertility in females without any other pathological conditions.

\section{METHODOLOGY}

This cross-sectional was conducted at Prime Ultrasound Center, Mughalpura Lahore, Pakistan, from March 2018 to September 2019. Sample size was calculated using WHO sample size calculator taking confidence interval $95 \%$, margin of error $5 \%$, reported prevalence of female infertility in Pakistan 7\%. ${ }^{10}$ The estimated sample size came out to be 100 females. Non-probability consecutive sampling technique was used.

Inclusion criteria all the married women of reproductive age, married for $>12-24$ months who had not conceived despite regular unprotected intercourse and females with no other uterine, endometrial or ovarian pathology were included in the study.

Exclusion criteria the patients who failed to provide serum hormone laboratory reports and patients on treatment of FSH and LH disorders were excluded.

After approval of synopsis from IRB, faculty of allied health sciences, the university of Lahore data form 100 females fulfilling inclusion criteria were taken. The data was taken after getting written informed consent. FSH levels of the patient was collected by qualified laboratory technician on day 12 of patient's menstrual cycle, labeled according to her assigned data sheet entry (serial number), properly at the spot and dispatched to the laboratory. Sonographic morphological (grayscale) and functional (doppler) assessment of the patient's ovaries was done on day 12 of her menstrual cycle to record Graafian Follicle size, perifollicular vascularity grade with power doppler and doppler indices with PW doppler.

Data were evaluated and analyzed with Statistical Package for the Social Sciences (SPSS) version 24. Normality of quantitative data was tested using ShapiroWilk's test found that, Age (years), FSH levels day 12 $(\mathrm{mlU} / \mathrm{mL})$ and Follicle size day $12(\mathrm{~mm})$ were not normally distributed. So, for non-normally distributed data non-parametric tests were applied. Median FSH levels and follicle size at day 12 were compared in Grades of perifollicular vascularity using Kruskal-Wallis $\mathrm{H}$ test. correlation was applied. The $p$-value $\leq 0.05$ was considered as significant.

\section{RESULTS}

A total of 100 females were taken in this study. The median age of females was 28 (30-25) years, ranging from 19 and 46 years. The median FSH levels at day 12 was $6(8.25-5.22) \mathrm{mlU} / \mathrm{ml}$ with minimum and maximum FSH values as 3.20 and $40 \mathrm{mlU} / \mathrm{ml}$. The median follicle size was 13.65 (16.04-10.84) (mm) with minimum and maximum size as $10 \mathrm{~mm}$ and $26 \mathrm{~mm}$ shown in Table-I. There were $61 \%$ females who had grade-I perifollicular vascularity, $24 \%$ females had grade-II and 15\% females had grade-III of perifollicular vascularity shown in Figure.

The median FSH levels at day 12 in females having grade-I was 5.60 (6.90-5.00), in females having grade-II was 7.50 (9.20-6.10) and among females having grade-III was 10.50 (12.37-8.35), and the median FSH in grade-I was 12.60 (15.60-10.55), in grade-II was 14.00 (15.88-10.85) There was statistically significantly 
Table-I: Descriptive statistics of age (years), FSH levels day $12(\mathrm{mlU} / \mathrm{mL})$ and Follicle size day $12(\mathrm{~mm})$.

\begin{tabular}{l|c|c|c}
\hline & $\begin{array}{c}\text { Age } \\
\text { (years) }\end{array}$ & $\begin{array}{c}\text { FSH levels } \\
\text { at day 12 } \\
\text { (mlU/mL) }\end{array}$ & $\begin{array}{c}\text { Follicle size } \\
\text { at day 12 } \\
(\mathbf{m m})\end{array}$ \\
\hline $\begin{array}{l}\text { Median } \\
\text { (IQR) }\end{array}$ & 28 & 6 & 13.65 \\
$(30-25)$ & $(8.25-5.22)$ & $(16.04-10.84)$ \\
\hline Minimum & 19 & 3.2 & 10 \\
\hline Maximum & 46 & 40 & 26 \\
\hline
\end{tabular}

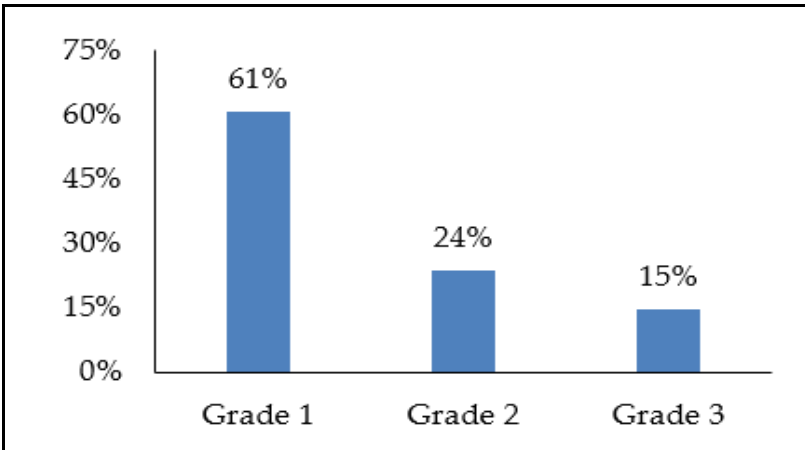

Figure: Distribution of perifollicular vascularity grade.

differenee between FSH group, follicle size day 12 $(\mathrm{mm})$ with grades $(p<0.001)$ and $(p=0.029)$ shown in Table-II.

Table-II: Comparison of FSH levels day $12(\mathrm{mlU} / \mathrm{mL})$ in all grades.

\begin{tabular}{l|c|c|c|c}
\hline \multirow{2}{*}{ Parameters } & \multicolumn{3}{|c|}{$\begin{array}{c}\text { Perifollicular Vascularity } \\
\text { Median (IQR) }\end{array}$} & \multirow{2}{*}{ p-value } \\
\cline { 2 - 4 } & Grade 1 & Grade 2 & Grade 3 & \\
\hline FSH levels & 5.60 & 7.50 & 10.50 & \\
day 12 & $(6.90-$ & $(9.20-$ & $(12.37-$ & $<0.001$ \\
$(\mathrm{mlU} / \mathrm{mL})$ & $5.00)$ & $6.10)$ & $8.35)$ & \\
\hline \multirow{2}{*}{ Follicle size } & 12.60 & 14.00 & 15.40 & \\
day 12 $(\mathrm{mm})$ & $(15.60-$ & $(15.88-$ & $(17.89-$ & 0.029 \\
& $10.55)$ & $10.85)$ & $13.54)$ & \\
\hline
\end{tabular}

On applying pair wise comparison significant difference was found of median FSH levels at day 12 and grades 1 vs grade $2(p<0.001)$, grades 1 vs grade 3 $(p<0.001)$ and grades 2 vs grade $3(p=0.016)$ and follicle size in grade-I vs. grade-III only significant $(p=0.007)$ shown in Table-III.

There was significant positive correlation between perifollicular vascularity grades and FSH levels day 12 $(\mathrm{mm})$ i.e. $\mathrm{r}=0.309, p$-value $<0.001$. There was positive but insignificant correlation between follicle size day $12(\mathrm{~mm})$ and FSH levels day $\mathrm{r}=0.141, p$-value $=0.161$.

Among obese cases there was positive insignificant correlation between perifollicular vascularity grades and FSH levels day $12(\mathrm{~mm})$ i.e. $\mathrm{r}=0.173$, $p$ - value 0.351 . In non-obese females significant positive correlation was found among perifollicular vascularity grades and FSH levels day $12(\mathrm{~mm})$ i.e. $\mathrm{r}=0.486$, $p$ value $<0.001$. Among obese females there was insignificant positive correlation between follicle size day $12(\mathrm{~mm})$ and FSH levels day $\mathrm{r}=0.041, p$-value=0.827. In non-obese females there was significant positive correlation between follicle size day $12(\mathrm{~mm})$ and FSH levels day $r=0.243, p$-value $=0.044$ as shown in Table-IV.

Table-III: Inter Group Comparison of FSH levels day 12 $(\mathrm{mlU} / \mathrm{mL})$ in all grades.

\begin{tabular}{l|c|c|c}
\hline \multirow{2}{*}{ Parameters } & \multicolumn{3}{|c}{ Perifollicular Vascularity ( $p$-value) } \\
\cline { 2 - 4 } & $\begin{array}{c}\text { Grade 1 Vs } \\
\text { Grade 2 }\end{array}$ & $\begin{array}{c}\text { Grade 1 Vs } \\
\text { Grade 3 }\end{array}$ & $\begin{array}{c}\text { Group 2 } \\
\text { Vs Group } \\
3\end{array}$ \\
\hline $\begin{array}{l}\text { FSH levels day } \\
12(\mathrm{mlU} / \mathrm{mL})\end{array}$ & $<0.001$ & $<0.001$ & 0.016 \\
\hline $\begin{array}{l}\text { Follicle size } \\
\text { day 12 }(\mathrm{mm})\end{array}$ & 0.664 & 0.007 & 0.094 \\
\hline
\end{tabular}

Table-IV: Correlation between serum FSH levels day 12 (mlU/mL), Perifollicular Vascularity Grade, Follicle size day $12(\mathrm{~mm})$ with respect to Body Mass Index.

\begin{tabular}{|c|c|c|c|}
\hline $\begin{array}{l}\text { FSH levels } \\
\text { day } 12 \\
(\mathrm{mlU} / \mathrm{mL})\end{array}$ & & & $p$-value \\
\hline \multirow{4}{*}{$\begin{array}{l}\text { Perifollicular } \\
\text { Vascularity } \\
\text { Grade }\end{array}$} & \multirow{2}{*}{ Obese } & Spearman's Correlation & 0.173 \\
\hline & & $p$-value & 0.351 \\
\hline & \multirow{2}{*}{$\begin{array}{l}\text { Non- } \\
\text { obese }\end{array}$} & Spearman's Correlation & 0.486 \\
\hline & & $p$-value & $<0.001$ \\
\hline \multirow{4}{*}{$\begin{array}{l}\text { Follicle size } \\
\text { day } 12(\mathrm{~mm})\end{array}$} & \multirow{2}{*}{ Obese } & Pearson Correlation & 0.041 \\
\hline & & $p$-value & 0.827 \\
\hline & \multirow{2}{*}{$\begin{array}{l}\text { Non- } \\
\text { obese }\end{array}$} & Pearson Correlation & 0.243 \\
\hline & & $p$-value & 0.044 \\
\hline
\end{tabular}

\section{DISCUSSION}

Infertility affects approximately $10-15 \%$ of couples globally. ${ }^{11}$ It effects women of all ages, in current study the mean age of females with primary infertility was $27.90 \pm 4.05$ years. In another study done on 215 women, the mean age was $30.384 \pm 3.15$ years. ${ }^{12}$ In our study the mean age was lesser as they reported. In another study the mean age of infertile females was even higher i.e. Dovom et al, in their study reported that mean age was $34.3 \pm 7.113$. Besides socioeconomic conditions, female infertility is result of diverse issues encompassing simple genital infections through anatomical issues to hormonal imbalance. The tested hormones include FSH, LH, Prolactin and Testosterone, out of these hormones FSH is the one which causes growth of 
the follicle and estrogen production. Disturbed FSH levels result thus in poor follicular development and hence anovulatory cycles. ${ }^{14} \mathrm{FSH}$ causes growth of ovarian follicle to preovulatory stage, and estrogen formation. Serum levels of FSH gradually decrease in mid to late follicular phase of menstrual cycle. So the growth of follicles except for the one that has already become dominant, stop and they undergo atresia. In a study, it was demonstrated that hormonal levels (LH, FSH, PRL and testosterone) were higher in women with primary infertility than control group, thus revealing that disturbed hormonal balance has important role in primary infertility. The study showed highly significant differences $(p<0.05)$ in the mean serum FSH levels in infertile group $12.95 \pm 17.53 \mathrm{mIU} / \mathrm{ml}(p$-values <0.05) vs $4.99 \pm 2.6 \mathrm{mIU} / \mathrm{ml}$ in control group. ${ }^{15}$ In another study Bheem et al, demonstrated higher FSH levels in women with primary infertility and found statistically significant difference $(p=0.0022)$ of serum FSH levels in infertile women vs fertile women i.e. $8.77 \pm 4.65 \mathrm{mIU} /$ $\mathrm{ml}$ vs $6.71 \pm 4.12$ respectively. ${ }^{16}$ In yet another study in Nigeria low serum levels of FSH, LH, and Progesterone were found in $30 \%$ infertile women as a result of secondary hypogonadism. ${ }^{17}$ In current study the FSH level was low as compared to above study in females with primary infertility i.e. $7.63 \pm 4.74 \mathrm{mlU} / \mathrm{ml}(3.20$ and $40 \mathrm{mlU} / \mathrm{ml})$. In this study $70(70 \%)$ patients came up with serum FSH level of $<8 \mathrm{mIU} / \mathrm{ml}, 29(29 \%)$ 8-20 $\mathrm{mIU} / \mathrm{ml}$ while $1(1 \%)$ had $>20 \mathrm{mIU} / \mathrm{ml}$. The reason may be that we took mean FSH levels at day 12 of MC while most of the studies have taken it at 3rd of MC.

It was found in a study that there were more chances of getting a mature oocyte following hCG, Gn $\mathrm{RHa}$, or kisspeptin administration on the day of trigger from follicles measuring $12-19 \mathrm{~mm} .{ }^{18}$ In the process of preparation for oocyte retrieval, administration of trigger is done only when the follicle has grown to a desired/appropriate size and is aimed at maturation of the oocytes. Mature oocyte is expected to be retrieved from follicles measuring 16-22 $\mathrm{mm}$ size on the day of oocyte retrieval. On the contrary in case of "too small" and "too large" follicles, it is well recognized that suitable response of administration of trigger and getting a mature oocyte is less likely in the case of former while in later case i.e. if the follicle gets too large the contained ovum may be "post mature" and incompetent to be fertilized. ${ }^{19}$ According to studies quoted for stimulation of growth, an every growing follicle requires a threshold level of FSH in circulation. The continuing development of preovulatory follicle requires this threshold level to be surpassed. Besides well recognized early follicular phase rise in serum FSH concentrations with age, maximum FSH concentrations also show great individual to individual variability as documented recently. In current study the mean follicle size was $14 \pm 3.61(\mathrm{~mm})(10 \mathrm{~mm}$ and $26 \mathrm{~mm})$. These included 36 (36\%) measuring <12 mm, $54(54 \%)$ measuring $12-19 \%$ and $10(10 \%)$ measuring $>19 \mathrm{~mm}$ in diameter. Although clinical value is still debated, an association in chances of conception and ovarian follicular vascularity have been reported to exist since early nineties. ${ }^{20}$

The hormonal changes in MC are translated into vascular changes in uterus and ovaries and can be detected by doppler ultrasound. These periodic hormonal changes in female genital organs can be detected by doppler measurements. Perifollicular Blood Flow (PFBF) corelates with oxygenation level of the follicle. Oocytes from well perfused (well oxygenated) follicles are related with better conception rates and pregnancy outcome where as those from poorly oxygenated (hypoxic) follicles are associated high rates of defects in chromosomal organization. ${ }^{21}$ In current study there were $61(61 \%)$ females who had grade-I perifollicular vascularity, 24 (24\%) females had grade-II and 15 (15\%) females had grade-III of perifollicular vascularity. Power Doppler assessment of PFBF dictates indirectly the competence level of the oocyte. TV PD increases delectation and visualization of perifollicular vascularity and Chui et al, graded PFBF into four grades; grade-I to grade-IV, depending upon the percentage of circumference of the follicle covered with blood flow on 2D PD. Grade-I being most poorly perfused and grade-IV as most highly perfused. They found higher rates of fertilization with increasing grade of perfusion /vascularity. In this study pregnancies occurred only in patients whose embryos were obtained from highly perfused follicles i.e. the ones having PFBF/perifollicular vascularity grade-III and IV with pregnancy rate of $12.5 \%$ and $61.5 \%$ respectively. However, the live pregnancies resulted only from PFBF/perifollicular vascularity grade-IV category follicles. Higher percentage of chromosomally abnormal embryos (triploids) was found associated with grade-I and II being 25 to $30 \%$ respectively in comparison to $<6 \%$ from highly vascularized follicles i.e. with grade-III and IV PFBF. 22

In a study from recent past, seventy-five mature ovarian follicles measuring $>16 \mathrm{~mm}$ in diameter from all 75 consecutive and unselected patients undergoing stimulated (with clomid) intrauterine insemination (IUI) cycles were assessed for perifollicular vascularity 
24 hours after Human Chorionic Gonadotropin (hCG) hormone administration with TV PD using subjective grading system. They came up with $10(13.33 \%), 24$ (32\%), $41(54.67 \%)$ and none (0\%) with grade-I, II, III and IV follicular vascularity. The vascularity was graded on the day of IUI, in follicles of $\geq 16 \mathrm{~mm}$ diameter independent of follicular size. High grade vascularity (grade-III) was associated with higher pregnancy rate than low grade vascularity (grade-II) i.e. 19.5\% and $12.5 \%$ respectively. Patients with grade-I vascularity did not get pregnant. The result was significant $(p$ $<0.05$ ). Early pregnancy loss was also significantly $(p<0.05)$ anticipated in grade-II and III follicles, which was more in grade-II (33.3\%) than in grade-III (12.5\%). Though the difference was not significant, it was found in the study that the mean baseline serum FSH levels were higher $(7.5 \pm 0.96,8.25 \pm 0.20)$ in low grade vascularity cycle as compared to high grade vascularity cycle $(6.42 \pm 0.59) .{ }^{23}$ In current study correlations were also found additionally, i.e. a significant positive correlation between perifollicular vascularity grades and FSH levels day $12(\mathrm{~mm})$ i.e. $\mathrm{r}=0.309, p$-value $<0.001$. A negative sign correlation was found between Resistive Index (RI) and FSH levels day 12 i.e. $\mathrm{r}=-0.268, p$-value= 0.007 .

In the light of current study's findings the relationship between FSH grades of Graafian follicle vascularity grades and doppler indices versus Graafian Follicle Vascularity grades are established. Additionally in current study, it was found that mean FSH levels at day 12 and mean follicle size increased as grades of Graafian Follicle Vascularity increased. Hence showing that graafian follicle vascularity may be used as method to evaluate primary infertility. As per author's knowledge such comparisons are not found in literature as correlation between serum levels of FSH and Graafian Follicle Vascularity on doppler in infertile females. Hence in future large studies at national and international level may be done to establish or to rule out the correlation between serum levels of FSH and Graafian Follicle Vascularity on doppler in infertile females. It may be of helpful in future for early diagnosis and then early treatment may offer the female to be pregnant and to improve their quality of life.

\section{CONCLUSION}

Graafian follicle vascularity on doppler can be helpful in diagnosis of primary infertility in females of unstimulated cycles. Since perifollicular vascularity has significant correlation with biochemical hormone levels and is independent of morphometry, doppler ultrasound can play a potential role not only in diagnosis of infertility but also reduce the costly hormone tests.

\section{Conflict of Interest: None.}

\section{Authors' Contribution}

AI: Main author, idea conception, SAG: Supervisor, idea, and write up, AH: Co-supervisor analysis and write up.

\section{REFERENCES}

1. Polis CB, Cox CM, Tunçalp O, McLain AC, Thoma ME. Estimating infertility prevalence in low-to-middle-income countries: an application of a current duration approach to Demographic and Health Survey data. Hum Reprod 2017; 32(5): 1064-1074.

2. Benksim A, Elkhoudri N, Addi RA, Baali A, Cherkaoui M. Difference between primary and secondary infertility in Morocco: frequencies and associated factors. Int J Fertil Steril 2018; 12(2): 142-146.

3. Hassan SUN, Siddiqui S, Friedman BD. Health status and quality of life of women seeking infertility treatments in Baluchistan, Pakistan. Health Qual Life Outcomes. 2017; 15(1): 139-142.

4. Katole A, Saoji AV. Prevalence of primary infertility and its associated risk factors in urban population of central India: A community-based cross-sectional study. Ind J Community Med 2019; 44(4): 337-341.

5. Marques P, Skorupskaite K, George JT, Anderson RA, Feingold KR, Anawalt B, . Physiology of GNRH and Gonadotropin Secretion. 2018, https:// pubmed.ncbi.nlm.nih.gov/25905297/

6. Jabbour SA. Follicle-Stimulating Hormone Abnormalities. Medscape, [Internet] Available at: https://emedicine.medscape. com/article/118810-overview (Accessed on March 12, 2018)

7. Reed BG, Carr BR, Feingold KR, Anawalt B, Boyce A, Chrousos $\mathrm{G}$, et al. The Normal Menstrual Cycle and the Control of Ovulation. 2018, [Internet] Available from: https:// pubmed.ncbi. nlm.nih.gov/25905282/

8. Thiyagarajan DK, Basit H, Jeanmonod R. Physiology, Menstrual Cycle. 2021 Sep 18. In: StatPearls. Treasure Island (FL): StatPearls Publishing; 2021, [Internet] Availabel from: https://pubmed. ncbi.nlm.nih.gov/29763196/

9. Sharma N, Saravanan M, Lakshmanan Saravanan M, Narayanan $\mathrm{S}$. The role of color doppler in assisted reproduction: A narrative review. Int J Repro Bio Med 2019; 17(11): 779-785.

10. Riffat S, Fazli S, Sikandar S, Khaula S, Faheem T. Prevalence of infertility in a cross section of Pakistani population. Pak J Zool 2010; 42(4): 389-393.

11. Tamrakar SR, Bastakoti R. Determinants of infertility in couples. J Nepal Health Res Counc 2019; 17(1): 85-89.

12. Haseena S, Umbardand SM. Clinico-demographic profile of patients with infertility at tertiary health care center. Int J Gynaecol 2017; 3(3): 84-86.

13. Dovom MR, Tehrani FR, Abedini M, Amirshekari G, Hashemi S, Noroozzadeh M. A population-based study on infertility and its influencing factors in four selected provinces in Iran (2008-2010). Iranian J Reporoduct Med 2014; 12(8): 561-566.

14. Raju GAR, Chavan R, Deenadayal M, Gunasheela D, Gutgutia R, Haripriya G, et al. Luteinizing hormone and follicle stimulating hormone synergy: A review of role in controlled ovarian hyperstimulation. J Hum Reprod Sci 2013; 6(4): 227-232.

15. Rashid BM, Mahmoud TJ, Nore BF. Hormonal study of primary infertile women. J Zankoy Sulaimani 2013; 15(2): 2-5.

16. Prasad B, Parmar D, Sharma N. A study on serum FSH, LH and prolactin levels among infertile women. Int J Medical Res Health Sci 2015; 4(4): 876-878. 


\section{Follicle Stimulating Hormone and Graafian Follicle Vascularity}

17. Digban KA, Adu ME, Jemikalajah JD, Adama S. Hormonal profile of some infertile women in Bida Nigeria. Libyan J Med Sci 2018; 2(1): 26-30.

18. Abbara A, Vuong LN, Ho VNA, Clarke SA, Jeffers L, Comninos AN, et al. Follicle Size on Day of Trigger Most Likely to Yield a Mature Oocyte. Front Endocrinol (Lausanne) 2018; 9(2): 193-198.

19. Revelli A, Martiny G, Delle Piane L, Benedetto C, Rinaudo P. A critical review of bi-dimensional and three-dimensional ultrasound techniques to monitor follicle growth: do they help improving IVF outcome?. Reprod Biol Endocrinol 2014; 12(2): 107-112.

20. Zhang Y, Yang J, Xu W. Study on relationship between perifollicular blood flow and in vitro fertilization-embryo transfer. J Nanjing Med Uni 2008; 22(1): 57-60.
21. Bauman R, Muravec UR. The Normal Ovary (Changes in the Menstrual Cycle). Ultrasound Imaging in Reproductive Medicine: Springer; 2014, [Internet] Available from; https://link. springer.com/book/10.1007/978-1-4614-9182-8

22. Chui D, Pugh N, Walker S, Gregory L, Shaw R. Follicular vascularity-the predictive value of transvaginal power doppler ultrasonography in an in-vitro fertilization programme: a preliminary study. Hum Repro (Oxford, England) 1997; 12(1): 191196.

23. Al-Ghazali BS, Al-Haris NR. Perifollicular vascularity as a potential variable affecting outcome in stimulated intrauterine insemination treatment cycles: by using transvaginal power Doppler. Al-Qadisiyah Med J 2012; 8(14): 63-82. 